\title{
Productividad laboral y la integración económica centroamericana: el caso de El Salvador
}

\author{
Luis René Cáceres ${ }^{1}$
}

\section{Resumen}

El propósito de este trabajo es identificar las variables que determinan la productividad laboral en El Salvador. Los resultados indican que la extrema apertura de su economía, así como la caída de su tasa de inversión desde mediados de los años noventa, han constituido frenos al dinamismo de la productividad laboral, lo que también se observa en los otros países centroamericanos. Se ha encontrado además que la productividad de un país recibe influencias positivas del dinamismo del empleo de calidad y de la inversión en los países vecinos. Este trabajo concluye indicando la conveniencia de restituir la protección a los sectores productivos de la subregión y de promover la calidad de la educación, la tecnología y la adquisición de conocimientos y destrezas.

\section{Palabras clave}

Empleo, mercado de trabajo, productividad laboral, medición, crecimiento económico, inversiones, integración económica, calidad de la educación, estadísticas de productividad, El Salvador

\section{Clasificación JEL}

D62, E26, F15, F43, O18, R11

\section{Autor}

Luis René Cáceres es Doctor en Economía de la Universidad de Utah (Estados Unidos). Correo electrónico: luisrenecaceres@gmail.com.

\footnotetext{
Para Raquel Eva Virginia Rosario, mi hija, salvadoreña tenaz.
} 


\section{Introducción}

Estudios recientes han señalado la persistente tendencia decreciente de la productividad laboral en los países latinoamericanos desde mediados de la década de 1970, después de un rápido crecimiento registrado en el período 1950-1970. Entre 2000 y 2015 la tasa promedio de crecimiento anual de la productividad laboral fue del 0,6\%, la más baja de todas las regiones del mundo, lo que, junto con el crecimiento de la tasa de empleo del 2,3\% anual, explica la baja tasa promedio de crecimiento económico, del 3\% anual, también la más baja de todas las regiones (OCDE, 2016; McKinsey, 2017).

Se espera que el papel impulsor de la tasa de empleo merme en el futuro, al caer dicha tasa al 1,1\% anual, en vista de la reducción de la tasa de fertilidad y del envejecimiento de la población. La implicación es que, si la productividad no aumenta con dinamismo, el crecimiento económico caería a una tasa cercana a la mitad de la que se registró entre 2000 y 2015 (OCDE, 2016; McKinsey, 2017).

En este trabajo se investigan los determinantes de la productividad laboral en El Salvador. En la sección II se presenta una breve reseña de la literatura reciente sobre la productividad en los países latinoamericanos, seguida, en la sección III, de una discusión de los datos y sus propiedades estadísticas. En la sección IV se exponen los resultados de la estimación de ecuaciones de cointegración que expresan el crecimiento anual de la productividad de El Salvador y de otros países centroamericanos, en términos de variables independientes asociadas a la inversión, el mercado laboral, el sector externo y el comportamiento de las economías de los otros países de la subregión. En la sección $V$ se analiza la interdependencia de la productividad de los países centroamericanos por medio de la calidad de la educación y sus implicaciones. El trabajo se cierra, en la sección VI, con una serie de conclusiones y recomendaciones.

\section{Reseña de literatura seleccionada}

Los estudios sobre la productividad laboral en los países latinoamericanos concuerdan en señalar que se ha verificado una marcada caída de la misma a partir de los años setenta, pero difieren en las explicaciones de ese hecho ${ }^{2}$. A continuación, se presenta una reseña de trabajos seleccionados sobre la productividad laboral en los países de América Latina.

Cole, Ohanian y Riascos (2005) llevaron a cabo un ejercicio de descomposición del crecimiento económico en base a una función de producción e informaron que la ratio de la mano de obra respecto de la población no era la causa del estancamiento del ingreso per cápita, ya que se ha mantenido en alrededor del $70 \%$ del valor de los Estados Unidos. Asimismo, la ratio del capital respecto de la mano de obra se ha mantenido en un valor cercano al 10\% de la de ese país. Los autores explican que el capital humano tampoco es la causa de dicho estancamiento, pues entre 1960 y 1990 el capital humano, medido como el promedio de las tasas de matrícula en los niveles educativos primario, secundario y terciario, ha presentado un aumento del 19\%. Sobre la base de estos datos, deducen que la explicación reside en la productividad total de los factores, que explicó el 66\% de la brecha de productividad.

Estos autores usan datos de las décadas de 1950 y 1960 para argumentar que han existido barreras a las importaciones y a la competencia, lo que deteriora la productividad; pero la realidad es que en ese período la productividad laboral era mayor que la correspondiente a los años posteriores a la aplicación por parte de los países de rebajas drásticas de los aranceles a las importaciones y otras medidas para motivar la competencia.

\footnotetext{
2 Syverson (2011) ha presentado una amplia reseña de la literatura sobre la productividad.
} 
Daude y Fernández-Arias (2010) usaron un modelo de función de producción para analizar la brecha del ingreso per cápita de América Latina con relación al de los Estados Unidos, en función de las brechas de capital por trabajador, de capital humano, de participación laboral y de productividad total de los factores. Los autores demuestran que, en promedio, la contribución del capital físico a la brecha del ingreso per cápita se ha mantenido constante, mientras que las contribuciones del capital humano y de la intensidad de mano de obra han decrecido. A la inversa, la contribución de la productividad a la brecha del ingreso per cápita se duplicó en el período, alcanzando un 37\% en 2005.

Palma (2011) ha argumentado que la caída marcada de la productividad después de 1980 se explica por la caída de la tasa de inversión, en lo que ha influido la contracción de la inversión pública en todos los países. Este autor apunta además que otra causa de la caída de la productividad laboral radica en la contracción del sector manufacturero de los países de América Latina. Una consecuencia ha sido la reducción del porcentaje de la mano de obra empleada en el sector manufacturero desde 1980, contrariamente al crecimiento del empleo en este sector que ocurrió entre 1950 y 1980. Esta caída está asociada con la apertura externa y otras políticas liberales en boga desde los años ochenta.

El autor afirma que, además de las bajas tasas de inversión (entre otros, en servicios e infraestructura) y la falta de una diversificación creciente de la capacidad exportadora, no cabe duda de que la considerable desatención de la manufactura desde el período de las reformas económicas es una de las causas fundamentales del problema de productividad de América Latina, especialmente en lo referente a su sostenibilidad a largo plazo (Palma, 2011).

McMillan y Rodrik (2011) desarrollaron un modelo para postular que la productividad laboral se puede incrementar de dos maneras: una, mediante un aumento de las inversiones en capital humano y del cambio tecnológico en los sectores, lo que llaman cambio de productividad interna; la otra, por el movimiento de mano de obra de sectores de baja productividad a aquellos de alta productividad, lo que denominan componente estructural. Los autores recalcan que entre 1950 y 1975 la región experimentó un rápido crecimiento de la productividad, del 4\%, del cual la mitad se originaba en el cambio estructural. Pero desde ese último año la evolución de la productividad ha mostrado otro patrón: la variación de la productividad en los períodos 1950-1975 y 1975-2005 debido al cambio dentro de los sectores fue la misma, del 1,8\% anual, pero la variación debido al componente estructural se volvió negativa en el segundo período y fue del -0,2\% anual. Apuntan también que este cambio ha ocurrido no obstante el aumento de la estabilidad macroeconómica, la mayor apertura al comercio exterior, la privatización y las políticas de estímulo al mercado.

De acuerdo con estos autores, la causa de la caída de la productividad laboral en América Latina radica en el movimiento de mano de obra del sector manufacturero al sector de servicios, que ocurrió como consecuencia de la drástica apertura al comercio internacional, lo que, además, condujo a la contracción del sector manufacturero, que hasta entonces había hecho una alta contribución a la productividad. Además de recordar los costos de la desindustrialización prematura para la productividad de toda la economía, los autores señalan que la competencia con las importaciones ha redundado en la contracción de muchas industrias y el traslado de la mano de obra hacia actividades menos productivas, como la agricultura y el sector informal. Afirman que una diferencia importante entre los países puede ser la capacidad que tengan para manejar las regresiones económicas; un rasgo notable del estilo de globalización de Asia es su doble vía: muchas actividades que compiten con las importaciones han seguido recibiendo apoyo y, al mismo tiempo, han surgido nuevas actividades orientadas a la exportación (McMillan y Rodrik, 2011).

Sosa, Tsounta y Kim (2013) usaron el método de la contabilidad del crecimiento económico por medio de una función de producción, para determinar las causas del crecimiento económico de una muestra de países latinoamericanos en el período 1980-2012. Los autores señalan que entre 2003 y 2012 la tasa de crecimiento de los factores determinaba 3,75 puntos porcentuales del crecimiento 
económico anual, mientras que la productividad total de los factores explicaba 0,75 puntos porcentuales. Los autores llevaron a cabo ejercicios para proyectar las tasas potenciales de crecimiento económico del período 2013-2017 y encontraron que no sería posible mantener el dinamismo del pasado debido a las restricciones para incrementar la participación laboral, incluida la de las mujeres, deficiencias en la calidad de la educación y el envejecimiento de la población.

Cavalcanti Ferreira, de Abreu Pessoa y Veloso (2014) emplearon una metodología de descomposición de las fuentes de crecimiento de 18 países latinoamericanos sobre la base de una función de producción, para cuantificar las contribuciones de los insumos en la determinación de la productividad. Los resultados mostraron que el promedio de la productividad total de los factores creció a una tasa del 0,82\% anual en el período 1960-1975. Sin embargo, entre 1980 y 2007 la productividad total de los factores decreció a una tasa anual del 0,88\%. Los autores pusieron de relieve la aparente contradicción que suponía el hecho de que la productividad en la región hubiera caído persistentemente después de la adopción de políticas de mercado, mientras que en los años sesenta y setenta, cuando predominaba un régimen de sustitución de importaciones, la productividad crecía con dinamismo.

Cáceres y Cáceres (2017) emplearon un modelo de vectores autorregresivos (VAR) con datos panel de siete países latinoamericanos para analizar la respuesta de la productividad laboral ante choques a determinadas variables. Los resultados indicaron que la productividad crecía ante aumentos de la inversión, del capital humano, de los salarios, del empleo de calidad y de las exportaciones, mientras que decrecía en respuesta a aumentos de la desigualdad, de la tasa de pobreza, del empleo a tiempo parcial y del autoempleo. Los autores explicaron el papel negativo del coeficiente de Gini en el crecimiento de la productividad total de los factores sobre la base del papel que la desigualdad tiene en el incremento del autoempleo y la reducción del empleo de calidad.

Los modelos discutidos, con la excepción de los que aplican McMillan y Rodrik (2011) y Cáceres y Cáceres (2017), se basan en la medición de la productividad total de los factores, lo que da lugar a varias interrogantes. En primer lugar, hay que tener presente la opinión de Solow, que ha sido recientemente enfatizada por Syverson (2011), de que la productividad total de los factores es el residuo de una ecuación de regresión y, así, es una "medida de nuestra ignorancia". Además, en los trabajos incluidos en la literatura reseñada no se discuten explícitamente los problemas inherentes a la medición de la productividad por medio de la productividad total de los factores, que pueden ser significativos en vista de la calidad menos que óptima de los datos empleados, y particularmente de la existencia en América Latina de factores climáticos que afectan el PIB y sus componentes y, por tanto, pueden tener incidencia en los residuos de las ecuaciones de regresión.

\section{El modelo}

A continuación se presenta la derivación de una ecuación para la productividad laboral sobre la base de una función del tipo Cobb-Douglas. Como punto de partida se plantea que el producto interno bruto, $Y$, está dado por:

$$
Y=A K^{a} L^{(1-a)}
$$

En esta expresión, $A$ representa la productividad total de los factores (PTF), $K$ es la cuantía de capital físico y $L$ la de la mano de obra. Al dividir por $L$ se obtiene una expresión para la productividad laboral:

$\frac{Y}{L}=A\left(\frac{K}{L}\right)^{a}$

De donde, en logaritmos, se obtiene: $\log \left(\frac{Y}{L}\right)=\log (A)+\operatorname{aLog}\left(\frac{K}{L}\right)$

De la expresión anterior se desprende que el aumento del capital por trabajador, así como el aumento de la productividad total de los factores, dan lugar al aumento de la productividad laboral. 
Al introducir la variable capital humano $(H)$ en la función de producción, el producto interno bruto está dado por:

$$
Y=A K^{a} H^{(1-a)}
$$

Si se supone que el capital humano es igual al producto de la cuantía de la mano de obra por su nivel de educación promedio, $h$, el PIB se puede expresar así:

$Y=A K^{a}(h L)^{(1-a)}$

Por tanto, la productividad laboral está dada por:

$\frac{Y}{L}=A\left(\frac{K}{L}\right)^{a} h^{(1-a)}$

En logaritmos:

$$
\log \left(\frac{Y}{L}\right)=\log (A)+a \log \left(\frac{K}{L}\right)+(1-a) \log (h)
$$

Al diferenciar la última expresión se obtiene que la tasa de crecimiento de la productividad laboral está determinada por las tasas de crecimiento de la productividad total de los factores, de la cantidad de capital por trabajador y del nivel de educación del país.

En la estimación de la ecuación anterior el punto clave es la medición del crecimiento de la PTF. Varios autores han estudiado la identificación de las variables que podrían servir de indicador indirecto (proxy) para representar el crecimiento de la productividad total de los factores. Isaksson (2007) agrupó los determinantes de la PTF en cuatro grupos. El primero se relaciona con la creación de conocimientos, lo que está asociado con las actividades de investigación y desarrollo, así como con la transmisión de conocimientos por medio del comercio exterior y la inversión extranjera directa. El segundo se relaciona con el capital humano, la infraestructura física y la existencia de un eficiente sistema financiero. El tercero abarca aspectos institucionales, de integración con el resto del mundo y de geografía. El cuarto se relaciona con aspectos de competencia y con la situación social.

Por su parte, Blyde y Fernández-Arias (2006) informaron que las siguientes variables eran importantes determinantes de la PTF: el número promedio de años de educación, la esperanza de vida al nacer, la apertura al comercio exterior, los términos de intercambio, las importaciones de maquinaria y equipo, la calidad institucional, el crédito al sector privado como porcentaje del PIB, la tasa de consumo del gobierno, la tasa de inflación y el diferencial cambiario en el mercado negro de divisas.

El modelo que será estimado en este trabajo se basa en la función de producción Cobb-Douglas con capital humano, discutida anteriormente, usando como indicadores del crecimiento de la PTF algunas de las variables que han sido identificadas como indicadores indirectos del crecimiento de la productividad laboral.

\section{Los datos y sus características}

La principal fuente de datos para este estudio son los World Development Indicators del Banco Mundial. Se llevaron a cabo pruebas de raíz unitaria para las variables; los resultados de la prueba Dickey-Fuller ajustada indicaron que todas eran integradas de orden 1 al nivel del $5 \%{ }^{3}$.

La trayectoria de la productividad laboral ${ }^{4}$ de El Salvador, en precios constantes de 2010, se muestra en el gráfico 1.

\footnotetext{
3 Los resultados de la prueba Dickey-Fuller ajustada, así como los valores promedios y las desviaciones estándar de las variables se pueden obtener mediante una solicitud al autor.

4 Los datos de productividad laboral se refieren a empleo observado y están expresados en precios de 2010.
} 


\section{Gráfico 1}

Productividad laboral de El Salvador, 1990-2016

(En millones de dólares de 2010)

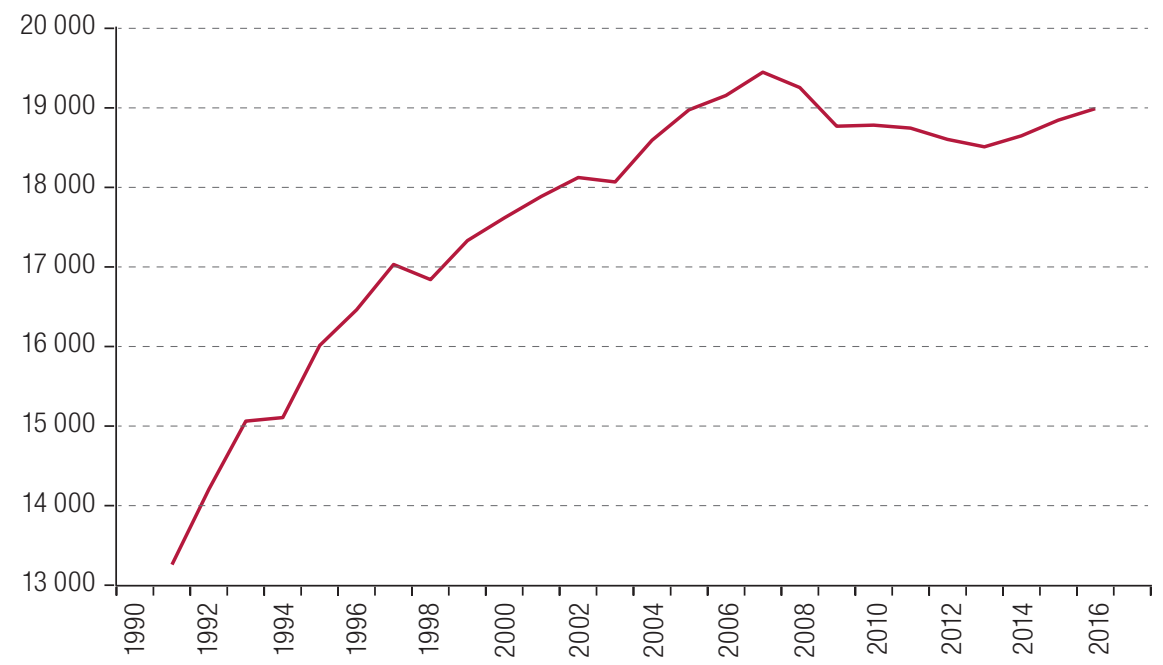

Fuente: Elaboración propia.

Se observa que esta variable decreció a partir de 2006 y empezó a recuperarse en 2012, pero su valor en 2016 todavía no superaba el valor máximo registrado en 2006. Esto se podría explicar por las repercusiones adversas de la crisis financiera mundial de 2008-2009, así como por la tendencia declinante del ahorro nacional, y por la reducción de los aranceles a las importaciones a partir de mediados de los años ochenta, lo que condujo a la desindustrialización (Cáceres, 2017 y 2018a). La extrema apertura de la economía ha dado lugar a la caída del empleo de calidad y al aumento del autoempleo, es decir, el empleo en el sector informal como lo define Loayza (1997).

\section{El modelo y sus estimaciones}

El modelo planteado para estimar el crecimiento de la productividad laboral se basa en una función de producción Cobb-Douglas con capital humano, desarrollada en párrafos anteriores. También se sigue la metodología de Rodrik (2013) para estimar la productividad laboral del Brasil, en la que la tasa de crecimiento de la productividad aumenta a medida que crece la inversión, mejora la mano de obra y se incrementa la productividad total de los factores. Así, las ecuaciones a ser estimadas siguen el modelo:

Crecimiento anual de la productividad laboral $=\mathrm{F}$ (inversión, indicadores de calidad de la mano de obra, crecimiento de la productividad total de los factores)

El papel de la inversión en la determinación de la productividad ha sido sustentado en varios estudios, especialmente por Jorgenson, Ho y Stiroh (2004), quienes mostraron que la inversión física era el principal determinante de la productividad en los Estados Unidos; por tanto, esta variable, en su versión tanto pública como privada, se usará en las estimaciones de este trabajo. Con relación a la calidad de la mano de obra, se usarán las tasas de autoempleo y de empleo de calidad, que Cáceres y Cáceres (2017) encontraron que tenían un importante papel como determinantes de la productividad laboral. Se supone, además, que el crecimiento de la productividad total de los factores está asociado con variables independientes que en diversos estudios han sido identificadas como sus determinantes, como se discutió en párrafos anteriores. 
Todas las ecuaciones fueron estimadas con datos del período 1990-2016 por medio de la metodología de mínimos cuadrados completamente modificados, desarrollada por Phillips y Hansen (1990), para tomar en cuenta el hecho de que algunas variables no eran estacionarias y que todas las variables eran endógenas. El primero de tres juegos de estimaciones para explicar el crecimiento de la productividad laboral de El Salvador se presenta en el cuadro 1.

\section{Cuadro 1}

Variable dependiente: tasa de crecimiento de la productividad laboral de El Salvador, 1992-2016

\begin{tabular}{|c|c|c|c|c|c|}
\hline \multirow{2}{*}{ Variables independientes } & \multicolumn{5}{|c|}{ Ecuaciones } \\
\hline & (1) & $(2)$ & (3) & (4) & (5) \\
\hline \multirow[t]{2}{*}{ Constante } & $-0,0078$ & $-2,0405$ & $-0,9760$ & 67,8085 & 88,6800 \\
\hline & $(0,22)$ & $(3,76)$ & $(0,40)$ & $(5,45)$ & $(6,64)$ \\
\hline \multirow[t]{2}{*}{ Gini } & $-0,3100$ & $-0,3740$ & $-0,3893$ & $-0,8322$ & $-0,9835$ \\
\hline & $(4,21)$ & $(3,50)$ & $(4,83)$ & $(10,16)$ & $(10,95)$ \\
\hline \multirow[t]{2}{*}{ Ipriv } & 1,1000 & 0,6576 & 0,6892 & & \\
\hline & $(5,48)$ & $(3,25)$ & $(4,22)$ & & \\
\hline \multirow[t]{2}{*}{ Ipriv(-2) } & & & & 0,4042 & 0,7006 \\
\hline & & & & $(4,21)$ & $(5,67)$ \\
\hline \multirow[t]{2}{*}{ Ipub(-2) } & 2,0201 & 1,6261 & 0,9859 & 1,3651 & 1,5571 \\
\hline & $(5,20)$ & $(3,34)$ & $(2,35)$ & $(5,46)$ & $(5,68)$ \\
\hline \multirow[t]{2}{*}{ Remesas } & $-0,2273$ & & & & \\
\hline & $(2,08)$ & & & & \\
\hline \multirow[t]{2}{*}{ Población } & & 0,6101 & & & \\
\hline & & $(2,74)$ & & & \\
\hline \multirow[t]{2}{*}{$\Pi$} & & & 0,0826 & & \\
\hline & & & $(3,54)$ & & \\
\hline \multirow[t]{2}{*}{ Tarifa } & & & $-0,2658$ & & \\
\hline & & & $(2,40)$ & & \\
\hline \multirow[t]{2}{*}{ Serv } & & & & $-0,9248$ & $-1,2554$ \\
\hline & & & & $(5,15)$ & $(6,71)$ \\
\hline \multirow[t]{2}{*}{ Manu } & & & & 0,9756 & 0,8115 \\
\hline & & & & $(10,11)$ & $(7,79)$ \\
\hline \multirow[t]{2}{*}{ Apertura(-1) } & & & & $-0,1241$ & \\
\hline & & & & $(5,32)$ & \\
\hline \multirow[t]{2}{*}{ Crédito } & & & & 0,1156 & 0,1213 \\
\hline & & & & $(2,20)$ & $(2,12)$ \\
\hline \multirow[t]{2}{*}{ Balanza } & & & & & $-0,2071$ \\
\hline & & & & & $(3,89)$ \\
\hline $\mathrm{R}$ cuadrado & 0,60 & 0,58 & 0,61 & 0,83 & 0,81 \\
\hline
\end{tabular}

Fuente: Elaboración propia.

Nota: Ipriv: tasa de inversión privada; Ipriv(-2): tasa de inversión privada con rezago de dos años; Ipub(-2): tasa de inversión pública con rezago de dos años; Remesas: razón entre remesas y PIB; Población: porcentaje de la población total que reside en la capital del país; TT: índice de términos de intercambio; Tarifa: arancel promedio aplicado a las importaciones; Serv: participación del sector de servicios en el PIB; Manu: participación de las manufacturas en el PIB; Apertura(-1): suma de las razones de exportaciones e importaciones respecto del PIB con rezago de un año; Crédito: razón de préstamo bancario al sector privado respecto del PIB; Balanza: déficit en la cuenta comercial como porcentaje del PIB.

La ecuación (1) del cuadro 1 muestra que el coeficiente del índice de Gini es negativo y muy significativo, lo que indica que la desigualdad socava el crecimiento de la productividad. La desigualdad ha disminuido en la mayoría de los países de la región desde inicios de la década de 2000, lo que varios autores han explicado por los aumentos del gasto social (González y Martner, 2012). En El Salvador, el coeficiente de Gini ha caído de manera persistente en años recientes, pasando de 46,7 en 2007 a 40,0 en 2016, lo que ha contribuido a evitar mayores deterioros de la productividad. Cáceres (2017) encontró que en los países de América Latina la desigualdad tiene una asociación positiva con el 
autoempleo, es decir, con el empleo precario, mientras que Chong y Gradstein (2004) concluyeron que la desigualdad redundaba en un crecimiento de la economía informal, es decir, del autoempleo, lo que tendría impactos negativos sobre la productividad.

La tasa de inversión privada tiene un coeficiente positivo y significativo, mientras que el coeficiente de la inversión pública solo fue significativo cuando entraba en la ecuación con un rezago de dos años, lo que podría significar que la inversión pública necesita un período de "incubación" para que su efecto se haga sentir sobre el crecimiento de la productividad laboral. Es preciso señalar que el coeficiente de la inversión pública es tres veces mayor que el de la inversión privada, por lo que el argumento que se ha sostenido con relación a la reducción del Estado para incrementar la productividad no tiene mérito.

La razón entre remesas y PIB (Remesas) tiene un coeficiente negativo y significativo, lo que podría reflejar que la ausencia de empleos y de servicios sociales de calidad motiva a las personas a emigrar5.

El porcentaje de la población total que reside en la ciudad capital (Población) se incluye en la ecuación (2) y tiene un coeficiente positivo y significativo. Esta variable puede interpretarse como un indicador de las economías de aglomeración que la ciudad capital ofrece a las empresas en términos de facilidades para contratar mano de obra especializada y para establecer relaciones de complementariedad con otras empresas. Carlino y Voith (1992), en el caso de los Estados Unidos, han presentado resultados en el sentido de que los principales determinantes de la productividad laboral de los estados son los correspondientes niveles de educación y de densidad de población, mientras que Decker, Thompson y Wohar (2009) mostraron que la productividad de dichos estados estaba determinada principalmente por el porcentaje de la población estatal que tenía un grado universitario y por el porcentaje de la población que vivía en áreas metropolitanas. Florida, Mellander y Stolarik (2016) mostraron, en el caso de los Estados Unidos, que las ventajas que las áreas metropolitanas ofrecían a las empresas para que tuviesen un buen desempeño radicaban en la abundancia de capital humano en las ciudades de alta densidad poblacional.

En la ecuación (3) se incluyen dos variables adicionales, el índice de términos de intercambio (TT) y el arancel promedio aplicado a las importaciones (Tarifa); sus coeficientes son significativos, positivo el primero y negativo el segundo. El primer resultado concuerda con la literatura en lo referente al importante papel de los términos de intercambio en el ciclo económico, mientras que el coeficiente negativo del arancel externo recalca la constatación de que la liberalización comercial ha conducido a caídas del crecimiento de la productividad laboral, lo que concuerda con los resultados de Palma (2011) y McMillan y Rodrik (2011).

Las ecuaciones (4) y (5) presentan los resultados con variables independientes relacionadas con el sector externo. En estas ecuaciones, la tasa de inversión privada entra con un rezago de dos años para reducir la alta correlación que tiene con la actividad manufacturera. La participación del sector de servicios en el PIB (Serv) y la participación de las manufacturas en el PIB (Manu) muestran coeficientes significativos, negativo el primero y positivo el segundo. Por su parte, el coeficiente de la razón de préstamo bancario al sector privado respecto del PIB es positivo y significativo. De especial importancia es el resultado de la ecuación (4) en el sentido de que el coeficiente de la suma de las razones de exportaciones e importaciones respecto del PIB con rezago de un año (Apertura (-1)) es negativo y significativo.

Esta variable se interpreta en la literatura como un determinante de la "eficiencia" económica, argumentándose que cuanto mayor sea menores serán las "distorsiones" causadas por la protección. Sin embargo, lejos de promover la eficiencia, la apertura ha conducido a la caída de la productividad laboral.

\footnotetext{
5 Esto contrasta con el impacto positivo que la migración tiene en la productividad de los países desarrollados: un aumento de 1 punto porcentual en la proporción de población de un país que es emigrante redunda en el largo plazo en un aumento de la tasa de crecimiento per cápita de dicho país del $2 \%$, principalmente a través del aumento de la productividad. Véase Jaumotte, Koloskova y Saxena (2016).
} 
La ecuación (5) introduce el déficit en la cuenta comercial como porcentaje del PIB (Balanza) como variable independiente y su coeficiente es negativo y significativo.

Un alto déficit en la cuenta comercial implicaría que el déficit en la cuenta corriente tendería a ser alto y, por lo tanto, habría una alta demanda por recursos externos. Esto podría establecer un límite a la inversión total, con consecuencias adversas sobre la productividad y el crecimiento económico. En la economía salvadoreña esta situación se vuelve crítica ante la baja tasa de ahorro nacional, de alrededor del $8 \%$ en los últimos años, de manera que mantener el déficit en cuenta corriente por debajo del 4\% requiere que la inversión total no supere el 12\%. Esto representa otra explicación del lento crecimiento económico de El Salvador; este tope a la tasa de inversión es 10 puntos porcentuales más bajo que el prevaleciente en los años setenta, cuando estaba vigente el modelo de sustitución de importaciones.

Se debe observar que el coeficiente de Gini es la variable que muestra el estadístico "t" de mayor dimensión en todas las ecuaciones que se presentan en el cuadro 1, lo que implicaría que la desigualdad constituye el marco en el que interactúan las otras variables que inciden en la productividad y, asimismo, pone en evidencia su papel en el debilitamiento de la eficiencia económica (CEPAL, 2018).

En el cuadro 2 se presentan los resultados con variables del mercado laboral como variables independientes. Las ecuaciones (1) y (2) muestran que las participaciones femenina y masculina tienen coeficientes negativos y significativos. Esto se podría explicar por el hecho de que la mano de obra salvadoreña se ubica principalmente en el sector subterráneo de la economía, el de servicios de baja calidad, en el que no se requieren destrezas ni habilidades especiales. Estos resultados deben compararse con los del estudio de Peterson, Mariscal e Ishi (2017) para el Canadá, en el que encontraron que el aumento de la oferta laboral de mujeres con altos niveles de educación había conducido al crecimiento acelerado de la productividad, en lo que había desempeñado un papel importante la existencia de redes de guarderías infantiles. Hay que hacer referencia al trabajo de Cáceres (2017), basado en una muestra transversal de datos de países latinoamericanos, en que se afirma que en la medida en que el gasto social per cápita aumenta también aumenta la tasa de empleo de calidad y cae la tasa de autoempleo, con el consecuente impacto positivo sobre la productividad.

En las ecuaciones (3) y (4) las tasas de autoempleo femenino y masculino muestran coeficientes negativo y positivo, respectivamente; el primero es marginalmente significativo y el segundo no lo es. Las ecuaciones (5) y (6) muestran que los coeficientes de las tasas de empleo industrial femenino y masculino, con rezagos de uno y dos años, respectivamente, son positivos y significativos. El coeficiente de la segunda tasa es de mayor dimensión que el de la primera $(0,4266$, frente a 0,2640$)$, lo que implica que el empleo industrial masculino tiene dos veces el impacto del empleo femenino en ese sector, en cuanto a su contribución al crecimiento de la productividad laboral. Esto permite ver que existen diferencias en la clase de empleos industriales que tienen mujeres y hombres, lo que revela la existencia de mercados laborales segregados por género y de discriminación de género. 


\section{Cuadro 2}

Variable dependiente: tasa de crecimiento de la productividad laboral de El Salvador, importancia de variables del mercado laboral, 1992-2016

\begin{tabular}{|c|c|c|c|c|c|c|}
\hline \multirow{2}{*}{ Variables independientes } & \multicolumn{6}{|c|}{ Ecuación } \\
\hline & (1) & (2) & (3) & (4) & (5) & (6) \\
\hline \multirow[t]{2}{*}{ Constante } & 23,6236 & 37,1976 & $-6,4960$ & 2,0010 & 0,4638 & $-10,3361$ \\
\hline & $(2,89)$ & $(2,84)$ & $(1,56)$ & $(0,41)$ & $(0,18)$ & $(3,46)$ \\
\hline \multirow[t]{2}{*}{ Gini } & $-0,4050$ & $-0,4409$ & $-0,3495$ & $-0,3742$ & $-0,5157$ & $-0,4742$ \\
\hline & $(4,83)$ & $(6,28)$ & $(4,54)$ & $(4,35)$ & $(5,44)$ & $(4,96)$ \\
\hline \multirow[t]{2}{*}{ Ipriv } & 0,7771 & 0,6091 & 0,6740 & 0,6371 & 0,5917 & 0,7573 \\
\hline & $(2,16)$ & $(4,18)$ & $(4,51)$ & $(3,38)$ & $(3,53)$ & $(4,54)$ \\
\hline \multirow[t]{2}{*}{ Ipub(-2) } & 0,9365 & 0,9757 & 0,9796 & 0,8996 & 0,9811 & 1,2831 \\
\hline & $(2,15)$ & $(2,67)$ & $(2,55)$ & $(2,00)$ & $(2,38)$ & $(3,15)$ \\
\hline \multirow[t]{2}{*}{$\pi$} & 0,0595 & 0,1072 & 0,0804 & 0,0860 & 0,0876 & 0,1112 \\
\hline & $(2,20)$ & $(5,09)$ & $(3,74)$ & $(3,45)$ & $(3,80)$ & $(4,28)$ \\
\hline \multirow[t]{2}{*}{ Tarifa } & 0,1411 & 0,3782 & 0,2136 & 0,2829 & 0,2278 & \\
\hline & $(1,16)$ & $(3,82)$ & $(2,00)$ & $(2,36)$ & $(2,05)$ & \\
\hline \multirow[t]{2}{*}{ Participación femenina } & $-0,4816$ & & & & & \\
\hline & $(3,02)$ & & & & & \\
\hline \multirow[t]{2}{*}{ Participación masculina } & & $-0,4700$ & & & & \\
\hline & & $(2,84)$ & & & & \\
\hline \multirow[t]{2}{*}{ Auto femenino } & & & $-0,0813$ & & & \\
\hline & & & $(1,70)$ & & & \\
\hline \multirow[t]{2}{*}{ Auto masculino } & & & & 0,0848 & & \\
\hline & & & & $(0,80)$ & & \\
\hline \multirow[t]{2}{*}{ Industrial femenino(-1) } & & & & & 0,2640 & \\
\hline & & & & & $(2,16)$ & \\
\hline \multirow[t]{2}{*}{ Industrial masculino(-2) } & & & & & & 0,4266 \\
\hline & & & & & & $(2,91)$ \\
\hline R cuadrado & 0,70 & 0,66 & 0,62 & 0,61 & 0,64 & 0,67 \\
\hline
\end{tabular}

Fuente: Elaboración propia.

Nota: Gini: coeficiente de Gini; Ipriv: tasa de inversión privada; Ipub(-2): tasa de inversión pública con rezago de dos años; TT: índice de términos de intercambio; Tarifa: arancel promedio aplicado a las importaciones; Participación femenina: tasa de participación laboral femenina; Participación masculina: tasa de participación laboral masculina; Auto femenino: tasa de autoempleo femenino; Auto masculino: tasa de autoempleo masculino; Industrial femenino: tasa de empleo industrial femenino; Industrial masculino: tasa de empleo industrial masculino.

\section{La productividad laboral y la integración económica centroamericana}

Las economías de aglomeración, a nivel nacional, permiten a las empresas disponer de amplias ofertas de mano de obra y servicios técnicos, que dan lugar a un "pool" de insumos especializados, ya sea relacionados con instalaciones industriales y equipo o con conocimientos. Es válido postular que en los países centroamericanos existen economías de aglomeración de tipo regional, ya que empresas de un país pueden acceder a la mano de obra y a los servicios técnicos de los otros países ${ }^{6}$. Crespi y otros (2008) han presentado información concluyente de que las empresas obtienen conocimientos de otras con las que tienen contactos frecuentes, como es el caso, por ejemplo, de los productores de sus insumos y la competencia. Es decir, el ámbito centroamericano es una plaza para la adquisición de conocimientos y buenas prácticas que están a disposición de las empresas nacionales para su selección e implementación, lo que conduciría a incrementar la productividad laboral nacional en mayor cuantía que si las empresas imitaran solamente las buenas prácticas de su propio país.

En el gráfico 2 se muestra la relación entre la tasa de empleo industrial femenino de Guatemala y el crecimiento de la productividad laboral de El Salvador.

\footnotetext{
6 Hay que apuntar que en Centroamérica los sectores privados nacionales se mantienen comunicados, entre otros medios, por la Federación de Cámaras de Comercio de Centroamérica y República Dominicana (FECAMCO) y que existen varias publicaciones de tipo gerencial financieras y económicas con cobertura regional.
} 


\section{Gráfico 2}

Tasas de empleo industrial femenino de Guatemala y de crecimiento de la productividad laboral de El Salvador, 1992-2016

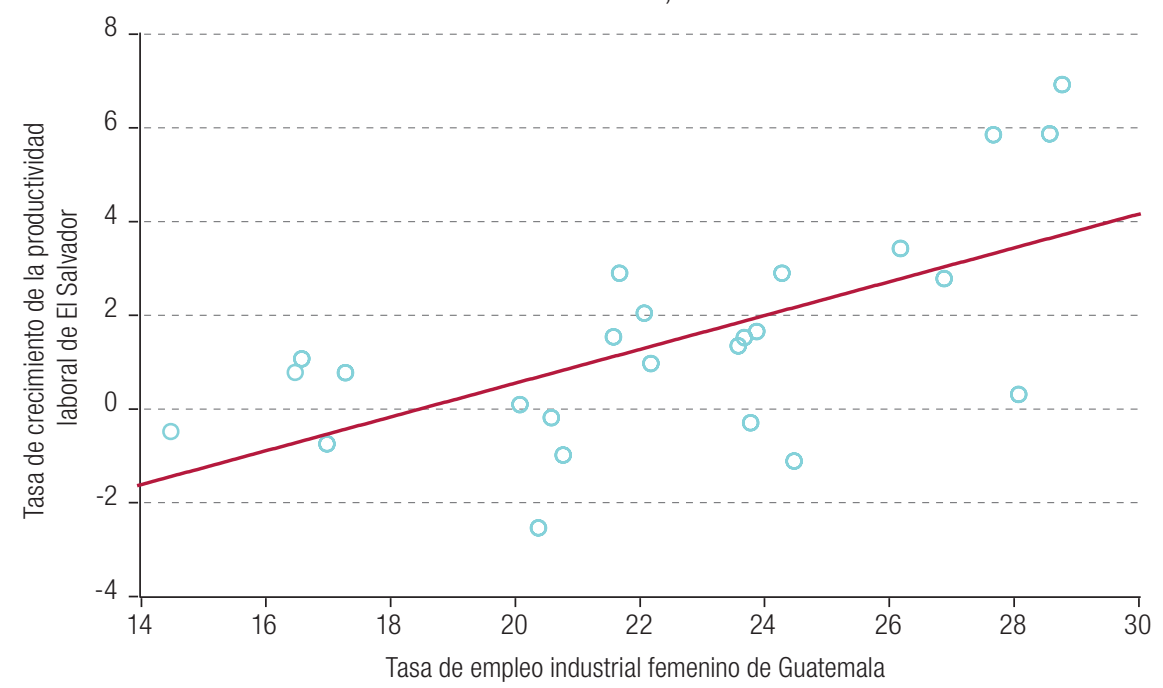

Fuente: Elaboración propia.

Con miras a detectar la existencia de economías de aglomeración regionales, se estimaron ecuaciones para el crecimiento de la productividad laboral de El Salvador en las que se incluyeron entre las variables independientes aquellas que correspondían a Guatemala, Honduras y Costa Rica. En estas ecuaciones se incluye la producción manufacturera de El Salvador para controlar por el incremento de las exportaciones salvadoreñas hacia los otros países ante el aumento de la inversión o ante el aumento del empleo industrial de estos, de manera que los impactos que recogen los coeficientes de la inversión pública y privada de estos países han sido depurados del incremento de la demanda agregada en los mismos.

En el cuadro 3 se presentan los resultados con variables de Guatemala, Honduras y Costa Rica. Las ecuaciones (1) y (2) muestran que la inversión privada de Guatemala con un rezago de un año (Guapriinvest(-1)) y la inversión pública de ese país con un rezago de dos años (Guapubinvest(-2)) tienen coeficientes positivos y significativos, lo que revela que los efectos de la inversión en Guatemala se derraman hacia la productividad de El Salvador. Esto podría interpretarse como el resultado de un mecanismo de aprendizaje por parte de las empresas salvadoreñas de las técnicas incorporadas en la nueva inversión privada de Guatemala; otra explicación podría ser que la inversión privada guatemalteca "obliga" a las empresas salvadoreñas a redoblar esfuerzos para aumentar su productividad a fin de contar con una mayor capacidad de enfrentar la competencia guatemalteca.

El impacto positivo de la inversión pública podría interpretarse como una consecuencia de la mejor infraestructura física en Guatemala, resultante de su inversión pública adicional, que contribuiría a reducir el costo del transporte de bienes entre los países.

La ecuación (3) muestra que el coeficiente de la tasa de empleo industrial masculino de Guatemala con rezago de un año (Guaempleoindustrialmasc(-1)) es positivo y significativo. Esto podría implicar que, ante el incremento del empleo industrial en Guatemala, las empresas salvadoreñas reconocen que tal dinamismo puede ocasionarles pérdidas de mercado y, en consecuencia, emprenden acciones para incrementar su productividad.

Se observa en la ecuación (4) que la tasa de inversión privada de Honduras (Hopriinv) presenta un coeficiente positivo y significativo; en la ecuación (5), el coeficiente de la tasa de empleo industrial masculino de Honduras (Hoempleoindustrialmasc) es positivo y significativo. En la ecuación (6), el 
coeficiente de la tasa de empleo industrial masculino de Costa Rica (CRempleoindustrialmasc) es positivo y significativo. Sin embargo, los coeficientes de las tasas de empleo industrial femenino de Honduras y Costa Rica resultaron no significativos. Esto podría interpretarse como un resultado concluyente en el sentido de que la transmisión de productividad entre países ocurre principalmente a través de las variables del mercado laboral masculino de calidad.

\section{Cuadro 3}

Variable dependiente: tasa de crecimiento de la productividad laboral de El Salvador, papel de la integración económica centroamericana

\begin{tabular}{|c|c|c|c|c|c|c|}
\hline \multirow{2}{*}{ Variables independientes } & \multicolumn{6}{|c|}{ Ecuaciones } \\
\hline & $(1)$ & (2) & (3) & (4) & (5) & (6) \\
\hline \multirow[t]{2}{*}{ Constante } & 9,2031 & 10,2771 & 0,5569 & 6,7234 & 7,2784 & 5,0682 \\
\hline & $(3,10)$ & $(3,04)$ & $(0,14)$ & $(2,16)$ & $(2,56)$ & $(1,95)$ \\
\hline \multirow[t]{2}{*}{ Gini } & $-0,5320$ & $-0,4491$ & $-0,5463$ & $-0,5387$ & $-0,5600$ & $-0,5631$ \\
\hline & $(7,86)$ & $(6,10)$ & $(7,27)$ & $(7,30)$ & $(8,68)$ & $(12,96)$ \\
\hline \multirow[t]{2}{*}{ Ipriv } & & 0,5393 & & & & \\
\hline & & $(2,95)$ & & & & \\
\hline \multirow[t]{2}{*}{ Ipriv(-2) } & 0,5475 & & 0,3314 & 0,5579 & 0,4980 & \\
\hline & $(4,77)$ & & $(2,10)$ & $(4,40)$ & $(4,37)$ & \\
\hline \multirow[t]{2}{*}{ |priv(-1) } & & & & & & 0,3886 \\
\hline & & & & & & $(3,56)$ \\
\hline \multirow[t]{2}{*}{ Ipub(-2) } & 1,8616 & 1,8098 & 0,8458 & 0,9550 & 1,5817 & 1,1084 \\
\hline & $(6,05)$ & $(4,35)$ & $(1,82)$ & $(2,02)$ & $(5,30)$ & $(4,87)$ \\
\hline \multirow[t]{2}{*}{ Manu } & 0,6607 & 0,4793 & 1,0677 & 0,8651 & 0,8959 & 0,6500 \\
\hline & $(4,91)$ & $(2,71)$ & $(6,41)$ & $(7,20)$ & $(8,20)$ & $(7,54)$ \\
\hline \multirow[t]{2}{*}{ Apertura } & $-0,2003$ & $-0,1826$ & $-0,1273$ & $-0,1910$ & $-0,1952$ & $-0,2740$ \\
\hline & $(7,12)$ & $(6,04)$ & $(3,66)$ & $(6,43)$ & $(7,24)$ & $(11,96)$ \\
\hline \multirow[t]{2}{*}{ Guapriinvest(-1) } & 0,2413 & & & & & \\
\hline & $(2,88)$ & & & & & \\
\hline \multirow[t]{2}{*}{ Guapubinvest(-2) } & & 0,4725 & & & & \\
\hline & & $(2,02)$ & & & & \\
\hline \multirow[t]{2}{*}{ Guaempeloindustrialmasc(-1) } & & & 0,1904 & & & \\
\hline & & & $(2,42)$ & & & \\
\hline \multirow[t]{2}{*}{ Hopriinv } & & & & 0,0945 & & \\
\hline & & & & $(2,66)$ & & \\
\hline \multirow[t]{2}{*}{ Hoempleoindustrialmasc } & & & & & 0,1128 & \\
\hline & & & & & $(3,64)$ & \\
\hline \multirow[t]{2}{*}{ CRempleoindustrialmasc } & & & & & & 0,7146 \\
\hline & & & & & & $(6,66)$ \\
\hline R cuadrado & 0,80 & 0,72 & 0,78 & 0,77 & 0,81 & 0,88 \\
\hline
\end{tabular}

Fuente: Elaboración propia.

Nota: En los casos en que no se menciona un país, las variables corresponden a El Salvador. Ipriv: tasa de inversión privada; Ipriv(-2): tasa de inversión privada con rezago de dos años; Ipriv(-1): tasa de inversión privada con rezago de un año; Ipub(-2): tasa de inversión pública con rezago de dos años; Manu: participación de las manufacturas en el PIB; Apertura: suma de las razones de exportaciones e importaciones respecto del PIB; Guapriinvest(-1): tasa de inversión privada de Guatemala con rezago de un año; Guapubinvest(-2): tasa de inversión pública de Guatemala con rezago de dos años; Guaempleoindustrialmasc(-1): tasa de empleo industrial masculino de Guatemala con rezago de un año; Hopriinv: tasa de inversión privada de Honduras; Hoempleoindustrialmasc: tasa de empleo industrial masculino de Honduras; CRempleoindustrialmasc: tasa de empleo industrial masculino de Costa Rica.

Los resultados del cuadro 3 muestran la existencia de un fenómeno que se podría llamar de economías de "emulación" o de "replicación" a nivel regional. Hay que mencionar que la Organización de Cooperación y Desarrollo Económicos (OCDE, 2016) ha recomendado que las empresas latinoamericanas promuevan y aprovechen la difusión de conocimientos que pueden provenir de aquellas que operan en la frontera tecnológica, que usualmente son multinacionales. En 
Centroamérica esta difusión de conocimientos y su aprovechamiento ocurre en las empresas y da lugar a las economías regionales centroamericanas.

Los resultados que se presentan en el cuadro 3 indican que podría estar operando en los países centroamericanos el fenómeno que Scitovsky (1957) llamó la "ducha fría" ocasionada por la competencia que obliga a las empresas a mejorar sus procedimientos y técnicas gerenciales, en el contexto de la teoría de la eficiencia X de Leibenstein (1966).

Se puede observar en las ecuaciones del cuadro 3 que las variables independientes de El Salvador continúan siendo significativas y que el coeficiente con el mayor estadístico "t" corresponde al coeficiente de Gini, seguido de la participación de la industria manufacturera en el PIB (Manu).

La red de impactos sobre la productividad es un resultado que podría ser exclusivo de países ubicados en una misma región geográfica, como los centroamericanos, ya que es válido esperar que un país que opta por la apertura unilateral enfrentaría diferencias de lenguaje y costumbres, el factor distancia, así como posibles prejuicios de tipo étnico, que podrían frustrar el intercambio de técnicas y conocimientos, con los países de los cuales importa; además, estos últimos podrían no estar interesados en compartir sus técnicas y sus buenas prácticas gerenciales con el país importador. La integración económica se ha descrito como un proceso de intercambio recíproco de mercados, pero se podría postular que esta reciprocidad, que es su característica más valiosa, va más allá de los mercados y conlleva compartir conocimientos.

\section{La productividad laboral en otros países centroamericanos}

Se estimaron ecuaciones que expresan el crecimiento de la productividad laboral de otros países centroamericanos, Costa Rica y Guatemala ${ }^{7}$. Los resultados se muestran en el cuadro 4.

Cuadro 4

Variables dependientes: tasas de crecimiento de la productividad laboral de Costa Rica y Guatemala

\begin{tabular}{lcc}
\hline & Costa Rica & Guatemala \\
\hline Constante & 21,2400 & $-0,2704$ \\
\cline { 2 - 3 } & $(3,40)$ & $(5,14)$ \\
\cline { 2 - 3 } & 1,300 \\
\cline { 2 - 3 } & $(3,62)$ \\
\hline CRManu & $-0,1192$ \\
\cline { 2 - 3 } & $(2,94)$ & \\
\hline CRTT & $-0,1800$ \\
\hline ESempleosalariofemen & $(0,47)$ & $(3,95)$ \\
\cline { 2 - 3 } & $-0,2800$ & $-8,1761$ \\
\hline Cuali & $(5,14)$ & $(12,88)$ \\
\hline GUAPreinv & 0,0050 & 0,6184 \\
\cline { 2 - 3 } & $(5,41)$ & $(5,42)$ \\
\hline
\end{tabular}

\footnotetext{
7 No se estimaron ecuaciones para la productividad laboral de Honduras y Nicaragua debido a limitaciones de datos.
} 
Cuadro 4 (conclusión)

\begin{tabular}{lcc}
\hline & Costa Rica & Guatemala \\
\hline GUEmpleosalariofeme & 0,5639 \\
\cline { 2 - 3 } GUManu(-1) & $(10,01)$ \\
\cline { 2 - 3 } & 9,8160 \\
\cline { 2 - 3 } & & $(9,28)$ \\
\hline GUTax & 3,4090 \\
\cline { 2 - 3 } & & $(3,16)$ \\
\hline R cuadrado & $-0,9571$ \\
\hline
\end{tabular}

Fuente: Elaboración propia.

Nota: CRManu: participación de las manufacturas en el PIB de Costa Rica; CRApertura(-1): suma de las razones de exportaciones e importaciones respecto del PIB de Costa Rica con rezago de un año; CRTarif: arancel promedio aplicado por Costa Rica a las importaciones; CRTT: índice de términos de intercambio de Costa Rica; ESempleosalariofemen: tasa de empleo asalariado femenino de El Salvador; Cuali: variable cualitativa que toma el valor de la unidad en los años 2006 y 2009, cuando la productividad laboral de Guatemala tuvo caídas significativas, y de cero en los otros años; GUAPreinv: tasa de inversión privada de Guatemala; GUEmpleosalariofeme: tasa de empleo asalariado femenino de Guatemala; GUManu(-1): participación de las manufacturas en el PIB de Guatemala con rezago de un año; GUTax: razón de la recaudación tributaria respecto del PIB de Guatemala; GUApertura: suma de las razones de exportaciones e importaciones respecto del PIB de Guatemala.

En ambas ecuaciones, el respectivo indicador de apertura tiene coeficientes negativos y significativos, mientras que los coeficientes de la participación de la industria manufactura en el PIB son positivos y significativos. También en ambas ecuaciones la tasa de empleo asalariado femenino de El Salvador presenta coeficientes positivos y significativos. El coeficiente del arancel de Costa Rica no es significativo, en tanto que el de sus términos de intercambio tiene un valor negativo y significativo, lo que se puede explicar en el contexto del análisis de Funke, Granziera e Iman (2008) en relación con los impactos de los términos de intercambio sobre el crecimiento económico. En la ecuación para Guatemala, la variable cualitativa Cuali representa los altos valores negativos del crecimiento de la productividad laboral en 2006 y en 2009, y sus tasas de inversión privada y de empleo asalariado femenino muestran coeficientes positivos y significativos. Hay que apuntar que el coeficiente de la razón de la recaudación tributaria respecto del PIB de Guatemala es positivo y significativo, es decir, el esfuerzo fiscal contribuiría al crecimiento de la productividad laboral, especialmente por apoyar la inversión pública y el gasto social.

\section{Derrames de productividad entre los países centroamericanos}

Los resultados que se presentan en los cuadros 3 y 4 implican que se puede postular la existencia de economías de integración, es decir, aquellas que surgen de una economía regional integrada. Dichos resultados indican que los países centroamericanos "comparten" su productividad, en virtud de los derrames de productividad que ocurren como consecuencia del crecimiento de la inversión y de la mano de obra industrial en cada uno de ellos. Este concepto no se ha reconocido en la literatura de la teoría de la integración económica. Otra implicación es que los países miembros de un mecanismo de integración económica tenderán a tener tasas de crecimiento de su productividad laboral, y de salarios, más altas que las que tendrían en la ausencia de la integración. Este es otro tema que tampoco ha sido reconocido en la literatura sobre integración económica. 
Por otra parte, existe una extensa literatura referente a los derrames de productividad que una empresa extranjera produce sobre otras empresas del país en que está radicada (Syverson, 2011). Estos derrames pueden originarse en la compra de insumos nacionales por parte de la empresa extranjera; en el acceso que las empresas nacionales tienen a tecnología y procedimientos modernos, y en el movimiento desde la empresa extranjera hacia las empresas nacionales de personal que lleva consigo conocimientos avanzados sobre técnicas gerenciales y de producción (Gorg y Strobl, 2001 y 2005). Esta literatura está relacionada exclusivamente con el papel de la inversión extranjera sobre la productividad agregada nacional del país receptor, pero el fenómeno de los derrames transnacionales de productividad, como es el caso centroamericano, no ha recibido atención.

\section{Interdependencia de la productividad laboral de los países centroamericanos por medio de la calidad de educación}

Hanushek y Woessmann (2007) han mostrado el importante papel que la calidad de la educación, medida por los puntajes en pruebas estandarizadas nacionales o internacionales, desempeña en el comportamiento de diversas variables económicas y sociales, lo que en el caso de los países latinoamericanos ha sido puesto en evidencia por Cáceres (2018b). En esta sección se demuestra que la interdependencia entre los países centroamericanos también se produce por medio de la calidad de la educación.

Sobre la base de la ecuación (4) del cuadro 3 se puede expresar el cambio del crecimiento de la productividad laboral de El Salvador en términos del aumento de la tasa de inversión privada de Honduras:

$\mathrm{D}$ (Crecimiento ES productividad) $=0,0945 \mathrm{D}$ (InversionprivHonduras)

Donde $D$ representa la primera diferencia de la variable entre paréntesis.

Usando datos de corte transversal de los países latinoamericanos, se estimaron ecuaciones para su inversión privada en términos de sus respectivos puntajes de lectura en tercer grado, tomados del Tercer Estudio Regional Comparativo y Explicativo (TERCE) (UNESCO, 2016), y del gasto público en educación como porcentaje del PIB:

$$
\begin{aligned}
& \text { Privinvest }=-39,2766+0,0801 \text { tercer grado lectura } \quad R 2=0,59 \\
& (2,68) \quad(2,55) \\
& \text { Privinvest }=5,7559+2,1946 \text { gasto público educación } \quad R 2=0,71 \\
& (1,36) \quad(2,55)
\end{aligned}
$$

Por tanto, los incrementos de las tasas de crecimiento de la productividad laboral de El Salvador ante aumentos de los puntajes de lectura en tercer grado y del gasto público en educación de Honduras son, respectivamente:

$$
\begin{aligned}
& D(E S \text { crecimiento productividad })=0,0076 \mathrm{D} \text { (tercer grado lectura Honduras) } \\
& D(E S \text { crecimiento productividad })=0,2074 \text { (gasto público educación Honduras) }
\end{aligned}
$$

Estas últimas ecuaciones indican que, si el puntaje de lectura en tercer grado de Honduras aumentara en 33 puntos porcentuales, lo que equivale a alcanzar el puntaje correspondiente a Colombia, la tasa de crecimiento de la productividad laboral de El Salvador aumentaría en 0,24 puntos porcentuales. Asimismo, el incremento del gasto público en educación de Honduras en 1 punto porcentual redundaría en el aumento de 0,21 puntos porcentuales de la tasa de crecimiento de la productividad laboral de El Salvador. 
Además, de la ecuación (1) del cuadro 3, que expresa el crecimiento de la productividad laboral de El Salvador en términos de un conjunto de variables independientes, incluida la tasa de inversión privada de Guatemala, se obtienen las siguientes ecuaciones, que expresan el cambio de la tasa de crecimiento de la productividad laboral salvadoreña en términos de los aumentos del puntaje de lectura en tercer grado y del gasto público en educación de Guatemala:

$$
\begin{aligned}
& D(E S \text { crecimiento productividad })=0,0193 \mathrm{D} \text { (tercer grado lectura Guatemala) } \\
& D(E S \text { crecimiento productividad })=0,5300 \mathrm{D} \text { (gasto público educación Guatemala) }
\end{aligned}
$$

De esta última ecuación se obtiene que si el gasto público en educación de Guatemala aumentara en 1,6 puntos porcentuales, es decir, tuviese el valor del Ecuador, la tasa de crecimiento anual de la productividad laboral de El Salvador aumentaría en 0,85 puntos porcentuales. Estos resultados indican que existen externalidades regionales de crecimiento de la productividad laboral impulsadas por la calidad de la educación.

En el gráfico 3, se muestra que los derrames de la calidad de la educación de un país centroamericano a otro conducen al incremento de la productividad regional de una manera sincrónica.

\section{Gráfico 3}

Interdependencia económica por medio de la calidad de la educación

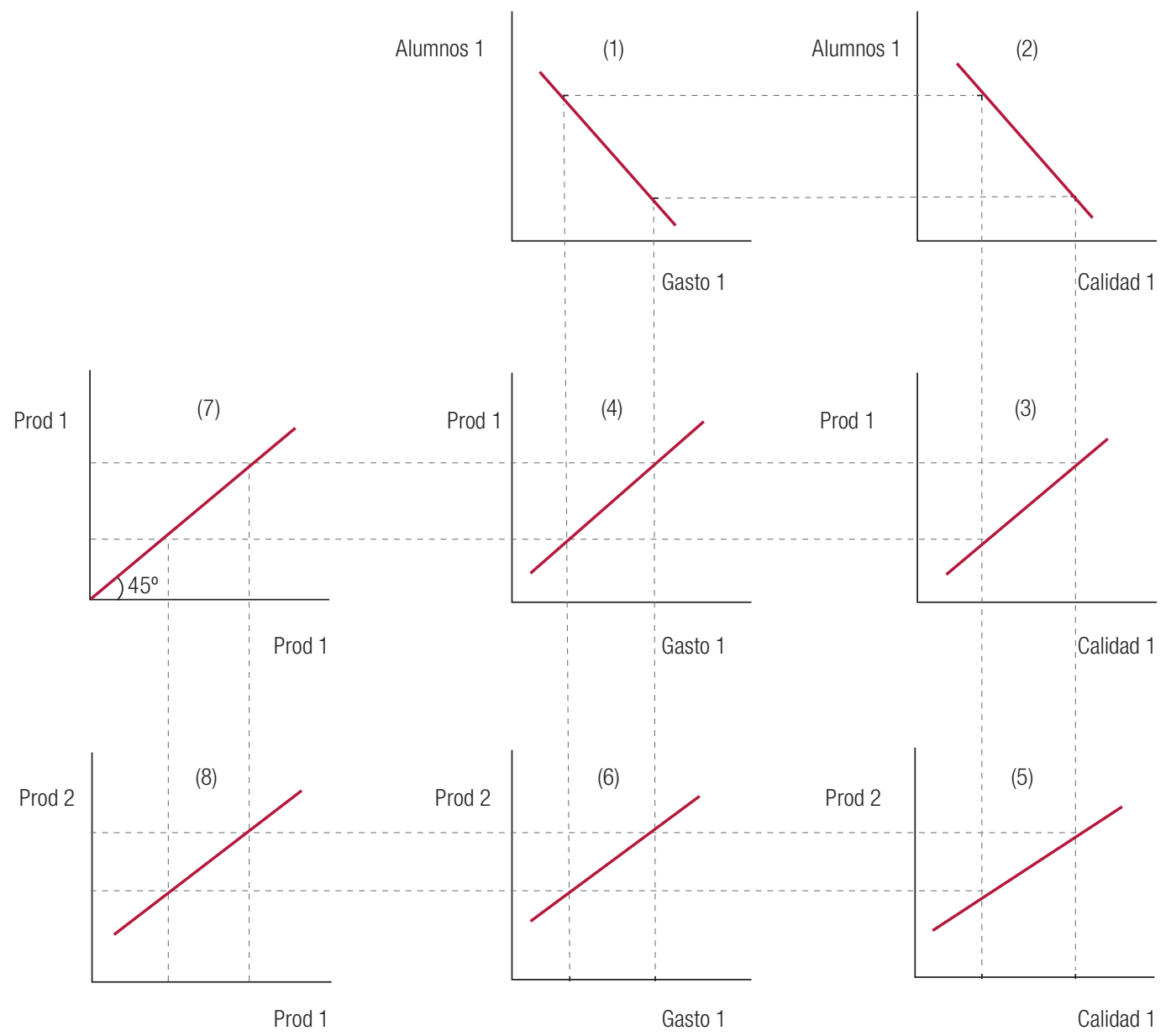

Fuente: Elaboración propia.

Nota: Las variables se refieren a dos países miembros de un mecanismo de integración, identificados como 1 y 2. Alumnos: número de alumnos por maestro en el país; gasto: gasto público en educación como porcentaje del PIB; calidad: calidad de la educación medida por los puntajes de lectura en tercer grado; prod: productividad laboral. 
El cuadrante (1) muestra la relación negativa entre el gasto en educación y el número de alumnos por maestro en el país 1, mientras que el cuadrante (2) indica que la disminución del número de alumnos por maestro conduce al aumento de la calidad de la educación ${ }^{8}$. En el cuadrante (3) se observa la relación positiva entre la calidad de la educación y el crecimiento de la productividad laboral en el país 1. Del cuadrante (3) y del cuadrante (1) se deriva la relación positiva entre el gasto en educación y la productividad laboral del país 1, graficada en el cuadrante (4). El cuadrante (5) muestra que la calidad de la educación en el país 1 da lugar al incremento de la productividad laboral del país 2; se observa también que el aumento del gasto en educación en el país 1 conduce al aumento de la productividad laboral en el país 2 (cuadrante (6)). Usando la línea de 45 grados del cuadrante (7), se obtiene, en el cuadrante (8), una relación positiva entre los aumentos de la productividad laboral de ambos países. Es decir, existe una armonía o sincronismo entre las productividades laborales nacionales en el área de integración económica. Esto significa que, en un mecanismo de integración como el centroamericano, el gasto público en educación redundaría en incrementos de la productividad laboral de mayor magnitud que los correspondientes en ausencia de integración. En otras palabras, la integración torna el gasto en educación nacional más "eficiente", o más "productivo", gracias a los derrames regionales de la productividad laboral ${ }^{9}$.

\section{La productividad laboral y la distribución de costos y beneficios de la integración}

Los resultados anteriores tienen implicaciones en la distribución de costos y beneficios de la integración: los países miembros de mayor desarrollo relativo podrían otorgar recursos financieros a los países de bajos niveles de desarrollo para que los destinaran a inversiones que incrementaran la calidad de la educación, lo que conduciría a que estos aumentaran su productividad y, por tanto, sus exportaciones, lo que podría redundar en una distribución más equilibrada del comercio intrarregional. A continuación, se analizan, en el gráfico 4, las implicaciones de la calidad de la educación en la distribución de los costos y beneficios de la integración.

En el cuadrante (1) se describe la relación entre el gasto en educación del país 1 (gasto1) y la calidad de la educación del país 1 (calidad1), y en el cuadrante (2) se presenta la asociación positiva entre la calidad de la educación del país 1 y la productividad laboral del país 1 (productividad1), según se demostró en Cáceres (2018b). En el cuadrante (3) se expresa la relación positiva entre productividad laboral del país 1 y las exportaciones del país 1 (exp1). A partir de los cuadrantes (1) y (3) se deriva, en el cuadrante (4), una relación positiva entre el gasto en educación y las exportaciones del país 1.

Supóngase que el país 1 exporta a su socio del programa de integración (el país 2) montos de bienes y servicios de baja cuantía en comparación con lo que compra del país 2 y, por lo tanto, el país 1 expresa malestar por la ausencia de equidad en el marco de la integración.

En respuesta, el país 2 le otorga al país 1 una transferencia anual que permite al país 1 incrementar su gasto en educación de g1 a g2. Como consecuencia, la calidad de la educación del país 1 aumenta de $c 1$ a $c 2$ y su productividad se incrementa de $p 1$ a $p 2$ y, por tanto, sus exportaciones al país 2 aumentan de e1 a e2.

\footnotetext{
8 La relación entre el número de estudiantes por maestro y los puntajes en pruebas internacionales de matemáticas y lectura es analizada por Cáceres (2018b).

9 El papel particular de la integración sobre la productividad se podría medir por la estimación de una ecuación de datos de corte transversal que expresara el crecimiento de la productividad laboral en términos de determinadas variables independientes, incluida una variable cualitativa que tomaría el valor 1 cuando se tratara de países que son miembros de mecanismos de integración.
} 


\section{Gráfico 4}

Calidad de la educación y costos y beneficios de la integración

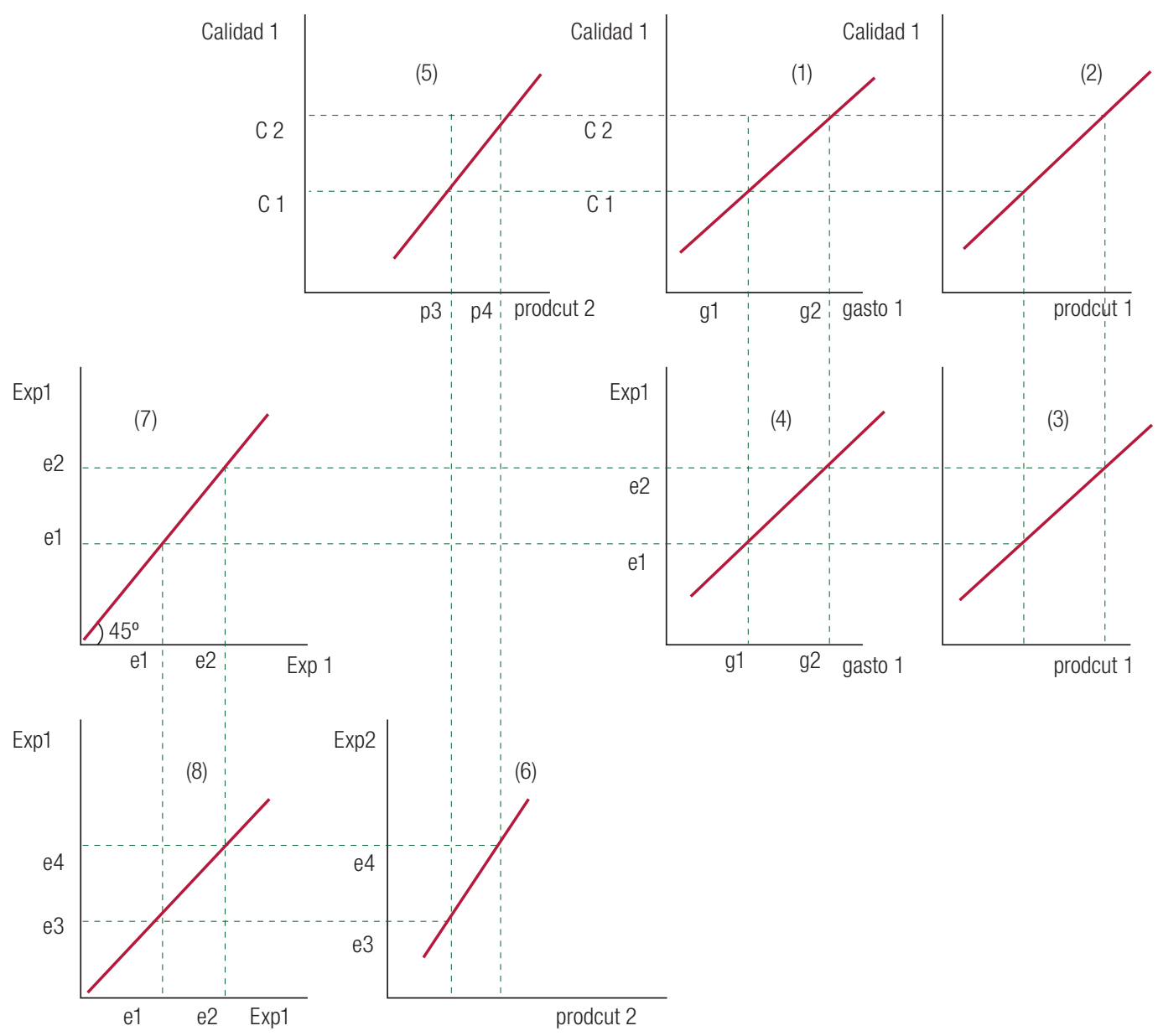

Fuente: Elaboración propia.

Nota: Las variables se refieren a dos países miembros de un mecanismo de integración, identificados como 1 y 2. Calidad: calidad de la educación medida por los puntajes de lectura en tercer grado; prodcut: productividad laboral; gasto: gasto público en educación como porcentaje del PIB; exp: exportaciones del país.

Hay que observar que la productividad del país 2 aumenta de p3 a p4 ante el incremento de la calidad de la educación del país 1 (como se mostró en el cuadrante (5) del gráfico 3); dicho aumento de la productividad se representa en el cuadrante (5) del gráfico 4. El aumento de la productividad del país 2 conduce al aumento de sus exportaciones, de e3 a e4, como se muestra en el cuadrante (6). A partir de este cuadrante y de la línea de 45 grados del cuadrante (7), se obtiene, en el cuadrante (8), una relación positiva entre los aumentos de las exportaciones de ambos países.

Se observa en el cuadrante (8) que la diferencia entre las exportaciones de los países 1 y 2 , es decir e4-e2, es baja con relación a la diferencia original, e3-e1, es decir, que la disparidad en el desempeño exportador se ha reducido.

Se debe recalcar que los beneficios macroeconómicos para el país 2 son iguales al incremento de sus exportaciones, es decir, e4-e3, multiplicado por el multiplicador keynesiano, que para los países centroamericanos es de alrededor de 2,5. El impacto multiplicador-es decir, el incremento del productopodría superar el monto de la transferencia original, sobre todo tomando en cuenta que cuando el país 1 alcance un nivel determinado de desarrollo estará en condiciones de asumir los gastos en educación adicionales que se financiaban con la transferencia recibida y que entonces el país 2 recibirá sin costo 
el impulso adicional a sus exportaciones, lo que, sin duda, compensaría sus erogaciones originales destinadas a las transferencias al país 1. Además, se producirían otros beneficios por el hecho de contar con un área de integración con una mayor disponibilidad de mano de obra calificada, que indudablemente contribuiría a la atracción de inversiones adicionales, nacionales y extranjeras.

\section{Conclusiones}

Los resultados de este trabajo presentados en los cuadros 1, 2 y 3 indican que la disminución de la productividad laboral de El Salvador se explica por las simultáneas caídas de la inversión y de la industria manufacturera, así como por la pérdida de buenos empleos del sector industrial. También han influido en este panorama los efectos negativos de la reducción arancelaria y de los altos déficits en la cuenta comercial de la balanza de pagos. Este resultado también se observa en los casos de Costa Rica y Guatemala (véase el cuadro 4). El carácter nocivo de la apertura extrema en los países centroamericanos no se ha sentido en plenitud, porque las remesas amplían la oferta de bienes de consumo importados, lo que puede crear un espejismo de prosperidad $^{10}$.

El deterioro de la productividad de El Salvador ha sido atenuado por la tendencia declinante de la desigualdad en la distribución del ingreso y por las repercusiones positivas de variables de los otros países centroamericanos, como el empleo industrial masculino y la inversión (véase el cuadro 3). La existencia de estos derrames implica que los países centroamericanos actúan como "amortiguadores" entre sí, en la medida en que contribuyen a contrarrestar las tendencias negativas de carácter nacional sobre la productividad.

Una conclusión de este trabajo es la conveniencia de restituir la protección a la producción nacional ante las importaciones con miras a favorecer el dinamismo del sector manufacturero y del empleo industrial. Hay que señalar que en 2016 El Salvador, así como los otros países centroamericanos, tenían aranceles a las importaciones, en promedio, de alrededor del $2 \%$, mientras que el promedio de los países latinoamericanos era del 12\%. La reducción de la extrema apertura externa contribuiría a la reindustrialización y, por tanto, a impulsar el cambio estructural favorable a la productividad, mediante el movimiento de mano de obra de los sectores de servicios de baja calidad al sector manufacturero.

En este contexto se debe apuntar que la información histórica de los países hoy desarrollados muestra que en sus etapas iniciales de desarrollo no implementaron las reformas que los países latinoamericanos llevaron a cabo en los años noventa; al contrario, implementaron prácticas proteccionistas que mantienen de diversas maneras hasta el presente. Se debe recalcar que el discurso de la liberalización económica no tiene asidero histórico, y su respaldo teórico es cuestionable en el mejor de los casos, como ha mostrado Rodrik (2006). Además, existe información que evidencia que las pérdidas de "eficiencia" y "bienestar" de un país por apartarse en sus políticas comerciales de los dictados de la ventaja comparativa son imperceptibles y que los países que se apartan de su ventaja comparativa tienden a exportar bienes manufacturados (Lectard y Rougier, 2018).

Hay que reconocer que la restitución de la protección sería una tarea ardua en El Salvador, así como en otros países de la región, en vista de que sus economías se han vuelto economías de importación y que existen intereses creados en relación con la continuidad de esa condición ${ }^{11}$.

\footnotetext{
${ }^{10}$ En algunos países latinoamericanos que también emprendieron programas de reformas "estructurales" en los años noventa, los aumentos de los precios de sus productos primarios generaron una bonanza económica; sin embargo, una vez que los precios cayeron, los países entraron en una etapa recesiva. Esta contracción económica no pudo ser contrarrestada por la "eficiencia" que la apertura económica iba a otorgar a las economías de la región.

11 Sobre la oposición a la transparencia de empresas y Gobiernos, a la competencia y las inversiones en capital humano, la OCDE (2016) señala que los intereses por mantener el statu quo pueden apoderarse del diseño de políticas o influir indebidamente en él para rechazar estas reformas y mantener sus rentas. Agrega que algunos de los costos pueden ser resultado de un diseño deliberado para crear rentas mediante el control de regulaciones y políticas, y que en el problema confluyen la inequidad históricamente alta y la concentración del poder político y económico que existen en los países de América Latina (pág. 11).
} 
Otra medida para incrementar la productividad laboral en El Salvador es mejorar sustancialmente la calidad de la educación. En este sentido, en vista de los derrames de productividad de un país a otro, originados en la mejora de la calidad de la educación, como se mostró en párrafos anteriores, sería conveniente la adopción en Centroamérica de compromisos nacionales para alcanzar determinadas metas de mediano plazo, relacionadas con el incremento del gasto en educación, la reducción del número de alumnos por maestro, mejoras de la infraestructura física de las escuelas y de los servicios de tecnología y aumentos de los resultados en las pruebas estandarizadas nacionales e internacionales. Esta medida generaría externalidades de integración y beneficios de mayor magnitud que si los esfuerzos fuesen emprendidos solamente en el plano nacional, sin una concertación y compromisos regionales. Para estos propósitos, es importante la adopción de pactos fiscales nacionales, en un contexto de compromiso regional, que abarcaran la determinación de destinar mayores montos de recursos a educación y salud, lo que redundaría en un impulso al dinamismo del comercio intrarregional y del crecimiento económico. Hay que señalar que en los países de América Latina existe una relación positiva entre productividad e ingresos tributarios como porcentaje del producto (Cáceres, 2018a).

De acuerdo con el modelo mostrado en el gráfico 4, al mejorar la calidad de la educación en un área de integración es posible impulsar las exportaciones de los países de bajo desarrollo relativo, de manera que las corrientes comerciales intrarregionales se volverían más equilibradas y, además, los derrames de productividad conducirían a mejorar la capacidad de exportación de todos los países miembros. Este es un beneficio que no se obtendría de la apertura unilateral.

Un resultado obtenido por McMillan y Rodrik (2011) que se debe destacar es que los países más grandes de América Latina tienden a retener su mano de obra en sectores de mayor productividad que los países más pequeños. Los autores sostienen que cuando se calcula un promedio regional que incluye el valor agregado y el empleo del mismo sector de varios países, dando mayor peso a los países más grandes, se observa que el componente de cambio estructural negativo se vuelve muy ligeramente positivo en América Latina, lo que indica que los flujos de empleo de los países latinoamericanos más grandes no se han movido tanto en la dirección incorrecta como los de los países más pequeños.

De este resultado se desprende otro importante papel de la integración económica regional, el hecho de que incrementa la productividad laboral nacional como resultado de las economías de escala derivadas del mercado ampliado y de los derrames de productividad entre países. La participación de las exportaciones dentro de América Latina en las exportaciones totales de la región ha declinado del $32 \%$ en 1998 al 22\% en $2010^{12}$. De allí surge el imperativo de impulsar la integración como un medio para contrarrestar las tendencias declinantes de la productividad en la región.

\section{Bibliografía}

Blyde, J. y E. Fernández-Arias (2006), "Why does Latin America grow more slowly?", Seminar Papers, № S-856, Washington, D.C., Banco Interamericano de Desarrollo (BID).

Cáceres, L. R. (2018a), "La productividad laboral en América Latina", Estudios Centroamericanos. (2018b), "Hechos estilizados sobre la calidad de la educación en América Latina", inédito. (2017), Shadow Economies in Latin America, Lambert Academic Publishers.

Cáceres, L. R. y S. Cáceres (2017), "Labor productivity and social policy in Latin America", Journal of Developing Areas, vol. 51, Nashville, Tennessee, Universidad Estatal de Tennessee.

Carlino, G. A. y R. Voith (1992), "Accounting for differences in aggregate State productivity", Regional Science and Urban Economics, vol. 22, Amsterdam, Elsevier.

Cavalcanti Ferreira, P., S. de Abreu Pessoa y F. A. Veloso (2014), "On the evolution of total factor productivity in Latin America", Economic Inquiry, vol. 51, New York, John Wiley.

\footnotetext{
${ }^{12}$ La productividad laboral de los países miembros de la Asociación de Naciones de Asia Sudoriental (ASEAN) es muy alta, lo que se puede relacionar con el hecho de que el comercio de estos países dentro de la Asociación representa el 50\% de su comercio externo total.
} 
CEPAL (Comisión Económica para América Latina y el Caribe) (2018), La ineficiencia de la desigualdad (LC/SES.37/3-P), Santiago, mayo.

Chong, A. y M. Gradstein (2004), "Inequality, Institutions, and Informality", Working Paper, 5/6, Washington, D.C., Banco Interamericano de Desarrollo (BID).

Cole, H. L., L. E. Ohanian y A. Riascos (2005), "Latin America in the rear mirror", Research Department Staff Report, № 351, Minneapolis, Banco Federal de Minneapolis.

Crespi, G. y otros (2008), "Productivity growth, knowledge flows, and spillovers", Working Paper, № 13959, Cambridge, Oficina Nacional de Investigaciones Económicas (NBER).

Daude, Ch. y E. Fernandez-Arias (2010), "On the role of productivity and factor accumulation in economic development in Latin America", Working Paper, No. 155, Washington, D.C., Banco Interamericano de Desarrollo (BID).

Decker, Ch. S., E. C. Thompson y M. E. Wohar (2009), "Determinants of labor productivity: the changing role of density", Regional Analysis and Policy, vol. 39, Jacksonville, Mid-Continent Regional Science Association.

Florida, R., Ch. Mellander y K. Stolarick (2016), "Human Capital in Cities and Suburbs", Annals of Regional Science, vol. 57, Springer.

Funke, N., E. Granziera y P. Iman (2008), "Terms of trade shocks and economic recovery", Working Paper, No. 08/36, Washington, D.C., Fondo Monetario Internacional (FMI).

González, I. y R. Martner (2012), "Superando el ‘síndrome del casillero vacío': determinantes de la distribución del ingreso en América Latina”, Revista CEPAL, № 108 (LC/G.2549-P), Santiago, Comisión Económica para América Latina y el Caribe (CEPAL).

Gorg, H. y E. Strobl (2005), "Spillovers from foreign firms through worker productivity: an emprirical investigation", The Scandinavian Journal of Economics, vol. 107, Wiley.

(2001), "Multinational companies and productivity spillovers: a meta analysis", The Economic Journal, vol. 111, Wiley.

Hanushek, E. A. y L. Woessmann (2007), Education Quality and Economic Growth, Washington, D.C., Banco Mundial.

Isaksson, A. (2007), "Determinants of total factor productivity: a literature review", Research and Statistics Branch Staff Working Paper, № 02/2007, Viena, Organización de las Naciones Unidas para el Desarrollo Industrial (ONUDI).

Jaumotte, F., K. Koloskova y S. C. Saxena (2016), "Impact of migration on income levels in advanced economies", Spillover Notes, № 8, Washington, D.C., Fondo Monetario Internacional (FMI).

Jorgenson, Dale W., Mun S. Ho y Kevin J. Stiroh (2004), "Will the U.S. productive resurgence continue?", Current Issues in Economics and Finance, vol. 10, Nueva York, Banco de la Reserva Federal de Nueva York.

Lectard, P. y E. Rougier (2018), "Can developing countries gain from defying comparative advantage? Distance to comparative advantage, export diversification and sophistication, and the dynamics of specialization", World Development, vol. 102, Amsterdam, Elsevier.

Leibenstein, H. (1966), "Allocative efficiency vs X efficiency", American Economic Review, vol. 56, Nashville, American Economic Association.

Loayza, N. (1997), "The economics of the informal sector. A simple model and some empirical evidence from Latin America”, Working Paper, NNo 1727, Washington, D.C., Banco Mundial.

Mckinsey Global Institute (2017), "Where will Latin America's growth come from?" [en línea] http://www. fundacionmicrofinanzasbbva.org/revistaprogreso/en/where-will-latin-americas-growth-come-from/.

McMillan, M. y D. Rodrik (2011), "Globalization, structural change and productivity growth", Working Paper, № 17143, Cambridge, Oficina Nacional de Investigaciones Económicas (NBER).

OCDE (Organización de Cooperación y Desarrollo Económicos) (2016), "Promoting productivity for inclusive growth in Latin America", Better Policies Series, París.

Palma, J. G. (2011), "Why has productivity growth stagnated in most Latin American countries since the neo-liberal reforms? Revised version", Cambridge Working Papers in Economics (CWPE), № 1030, Cambridge University.

Peterson, B., R. Mariscal y K. Ishi (2017), "Women are key for future growth: evidence from Canada", IMF Working Paper, No 17/166, Washington, D.C., Fondo Monetario Internacional (FMI).

Phillips, P. C. B. y B. E. Hansen (1990), "Statistical inference in instrumental variables regressions with I(1) processes", Review of Economic Studies, vol. 57, Oxford, Oxford University Press.

Rodrik, D. (2013), "Productivity growth: lessons for Brazil from other countries" [en línea] https://drodrik. scholar.harvard.edu/files/dani-rodrik/files/productivity-growth-lessons-for-brazil-from-other-countries.pdf. 
(2006), "Goodbye Washington Consensus, hello Washington confusion", Journal of Economic Literature, vol. 44, Nashville, American Economic Association.

Scitovsky, T. (1957), Economic Theory and Western European Integration, Londres, Allen \& Unwin.

Sosa, S., E. Tsounta y H. S. Kim (2013), "Is the growth momentum in Latin America sustainable?", Working Paper, No 13/109, Washington, D.C., Fondo Monetario Internacional (FMI).

Syverson, Ch. (2011), "What determines productivity?", Journal of Economic Literature, vol. 49, Nashville, American Economic Association.

UNESCO (Organización de las Naciones Unidas para la Educación, la Ciencia y la Cultura) (2016), Reporte técnico. Tercer Estudio Regional Comparativo y Explicativo (TERCE), Santiago. 